\title{
PERBANDINGAN KEJADIAN RETENSI URIN ANTARA PERSALINAN DENGAN VAKUM EKSTRAKSI DAN PERSALINAN NORMAL
}

\author{
Nurul Hikmah Petrana ${ }^{1}$, Ova Emilia ${ }^{2}$, Heru Pradjatmo ${ }^{3}$
}

\begin{abstract}
Background: Urinary retention after vaginal delivery is a common problem with incidence $1.7 \%-17.9 \%$. Assissted vaginal delivery is one risk factor for the occurence of urinary retention.

Objective: to compare urinary retention between normal vaginal delivery and assissted vaginal delivery using extraction vacum, and evaluate factors related to urinary retention.

Method: The study was prospective cohort design, conducted in 3 hospitals and 2 primary health centres during 6 month period since September 2013- February 2014. Subjects were divided into two groups i.e. normal delivery and assissted delivery using extraction vacum, each 118 subjects. Events of urinary retention was assessed and also related factors were identified. Analysis used Chi-Square test, Fisher test and also logistic regression analysis.

Result and Discussion: In total 236 subjects were involved, there was no difference in age and parity among the subjects. Incidence of urinary retention among extraction vacum delivery group was higher $(32.2 \%)$ compare to normal delivery (11.9\%). Multivariate analysis using logistic regression showed that extraction vacum ( $p=0.074$; OR $2.71 ; 95 \% \mathrm{Cl} 1.55-4.73$ ), baby weight $(\mathrm{p}=0.230$; OR $1.95 ; 95 \% \mathrm{Cl} 0.65$ 5.84 ) and perineal injury ( $p=0.614$; OR $1.35 ; 95 \% \mathrm{Cl} 0.41-4.36)$ were not significant risk factors for urinary retention. Length of labour ( $p=0.003 ; \mathrm{OR} 3.71 ; 95 \% \mathrm{Cl} 1.55-8.86)$ and parity $(\mathrm{p}=0.023 ; \mathrm{OR} 2.29 ; 95 \% \mathrm{Cl}$ 1.2-4.66) were significant risk factors for urinary retention.

Conclusion: Urinary retention is higher among vaginal delivery with extraction vacum compare to normal delivery. Length of labour and parity are external factors related to urinary retention.
\end{abstract}

Keywords: Assissted vaginal delivery, extraction vacum, normal delivery, urinary retention, postpartum

\section{ABSTRAK}

Latar Belakang: Retensi urin postpartum pada persalinan vaginal relatif sering terjadi, dilaporkan insidensinya antara $1.7 \%-17.9 \%$. Proses persalinan vaginal berbantu merupakan salah satu faktor risiko kejadian retensi urin.

Tujuan: membandingkan persalinan vaginal yang normal dan persalinan vaginal dengan vakum ekstraksi serta faktor yang mempengaruhi kejadian retensi urin.

Metode: Penelitian dilakukan dengan rancangan kohort prospektif, dilakukan di 3 Rumah Sakit dan 2 Puskesmas selama 6 bulan sejak September 2013- Februari 2014. Subyek dibagi menjadi 2 kelompok yaitu kelompok persalinan vaginal normal dan kelompok persalinan dengan vakum ekstraksi, masing-masing 118 sampel. Kemudian dihitung kejadian retensi urin dan faktor-faktor yang mempengaruhi. Analisis penelitian dilakukan uji Chi-Square dan uji Fisher serta analisis regresi logistik.

Hasil dan Pembahasan: Subyek penelitian yang terlibat 236 dan tidak ada perbedaan bermakna pada usia dan paritas. Kejadian retensi urin pada persalinan vakum ekstraksi lebih besar $(32,2 \%)$ dibanding

$\overline{\text { 1,2,3 Departemen Obstetri \& Ginekologi Fakultas Kedokteran Universitas Gadjah Mada/RS.Dr. Sardjito Yogyakarta }}$ 
pada persalinan vaginal normal (11,9\%). Analisis multivariat regresi logistik menunjukkan vakum ekstraksi $(p=0,074$; OR 2,71; 95\% Cl 1,55-4,73), berat janin ( $p=0,230$; OR 1.95; 95\% Cl 0.65-5.84) dan trauma perineum ( $p=0,614$; OR $1.35 ; 95 \% \mathrm{Cl} 0,41-4,36)$ bukan merupakan faktor risiko bermakna terjadinya retensi urin. Lama persalinan ( $p=0,003 ; \mathrm{OR} 3,71 ; 95 \% \mathrm{Cl} 1,55-8,86)$ dan paritas $(p=0,023 ; \mathrm{OR} 2,29 ; 95 \% \mathrm{Cl}$ 1,2-4,66) merupakan faktor risiko bermakna terhadap kejadian retensi urin.

Kesimpulan: Kejadian retensi urin lebih tinggi pada persalinan vaginal dengan vakum ekstraksi dibanding persalinan normal. Lama persalinan dan paritas merupakan faktor luar yang berpengaruh terhadap kejadian retensi urin.

Kata kunci: Persalinan dengan vakum ekstraksi, persalinan normal, retensi urin, postpartum

\section{PENDAHULUAN}

Retensi urin postpartum pada persalinan vaginal relatif sering terjadi, dilaporkan insidensinya antara 1,7\%-17,9\%. Pada suatu penelitian disebutkan dari 768 pasien, kejadian retensi urin pada persalinan normal sebanyak $9,7 \%$, dan pada persalinan dengan instrumen sebanyak $15,8 \%{ }^{1}{ }^{1}$ Penelitian oleh Yustini dkk di FKUI-RS Cipto Mangunkusumo tahun 2009 menunjukkan angka kejadian disfungsi kandung kemih postpartum sebanyak 9-14\% dan setelah persalinan yang menggunakan assisted labor (ekstraksi forsep), meningkat menjadi $38 \%{ }^{2}$

Perubahan fisiologi selama kehamilan, penggunaan analgesia regional, persalinan dengan instrumen, trauma perineum, nulipara dan persalinan yang lama dihubungkan dengan penyebab retensi urin. Deteksi awal retensi urin persisten sangat penting untuk mencegah kerusakan yang irreversibel akibat overdistensi kandung kemih. Satu episode overdistensi kandung kemih bila tidak didiagnosis dan di terapi secara dini dapat menyebabkan retensi urin postpartum persisten dan kerusakan yang irreversibel pada muskulus detrusor dengan infeksi traktus urinarius rekuren dan kesulitan berkemih menetap. ${ }^{3}$ Penelitian ini bertujuan untuk membandingkan pengaruh persalinan normal dan persalinan vaginal vakum ekstraksi terhadap kejadian urin, serta mengevaluasi faktor luar lain yang mempengaruhi.

\section{METODE}

Penelitian ini merupakan studi cohort prospektif. Subyek penelitian terdiri dari semua pasien yang menjalani persalinan vaginal mulai bulan September 2013-Februari 2014 di RSUD Bantul, RSUP Klaten, RSUD Bantul, Puskesmas Mergangsan dan Puskesmas Tegalrejo yang memenuhi kriteria inklusi dan eksklusi. Subjek dibagi menjadi 2 kelompok persalinan yaitu persalinan dengan vakum ekstraksi sebanyak 118 pasien dan persalinan vaginal normal sebanyak 118 pasien. Kedua kelompok diikuti sampai 6 jam periode postpartum, apakah dapat berkemih spontan atau tidak. Setelah berkemih spontan, dilakukan kateterisasi dan dihitung jumlah sisa urin. Jika selama 6 jam pasien tidak dapat berkemih spontan atau selama 6 jam dapat berkemih spontan tetapi residu urin setelah katetrisasi lebih dari $150 \mathrm{ml}$, maka dikatakan retensi urin. Analisis univariat digunakan untuk melihat karakteristik subyek penelitian dan homogenitas. Analisis bivariat yang digunakan adalah uji Chi square untuk menghitung RR dan confidence interval $(\mathrm{Cl})$. Bila nilai expected count dari satu sel atau lebih kurang dari 5 digunakan uji Fisher. Analisis multivariat menggunakan analisis multivariat regresi logistik. 
HASIL DAN PEMBAHASAN

Tabel 1. Karakteristik subyek penelitian

\begin{tabular}{lcc}
\hline Karakteristik & $\mathbf{n}$ & $\%$ \\
\hline Umur & & \\
$\quad<35$ tahun & 198 & 83,9 \\
$\quad \geq 35$ tahun & 38 & 16,1 \\
Paritas & & \\
$\quad$ Nulipara & 95 & 40,3 \\
$\quad$ Bukan & 141 & 59,7 \\
Lama persalinan & & \\
$\quad \geq 12$ jam & 40 & 16,9 \\
$\quad<12$ jam & 196 & 83,1 \\
Trauma Perineum & & \\
$\quad$ Ya & 195 & 82,6 \\
$\quad$ Tidak & 41 & 17,4 \\
Berat janin & & \\
$\quad \geq 4000$ gr & 20 & 8,5 \\
$\quad<4000$ gr & 216 & 91,5 \\
\hline
\end{tabular}

Karakteristik subyek secara keseluruhan yaitu usia subyek penelitian berkisar antara 17 tahun sampai dengan 44 tahun. Usia rata-rata subyek penelitian $28 \pm 6,20$ tahun, usia terbanyak adalah 34 tahun. Jumlah paritas terbanyak adalah dua $(55,9 \%)$ dengan mean (rata-rata paritas) 1,73 .

Tabel 2. Komparabilitas antara kelompok penelitian

\begin{tabular}{|c|c|c|c|c|c|}
\hline \multirow{3}{*}{ Karakteristik } & \multicolumn{5}{|c|}{ Jenis Persalinan } \\
\hline & \multicolumn{2}{|c|}{ Vakum ekstraksi } & \multicolumn{2}{|c|}{ Normal } & \multirow[t]{2}{*}{$P$} \\
\hline & $\mathrm{n}$ & $\%$ & $\mathrm{n}$ & $\%$ & \\
\hline \multicolumn{6}{|l|}{ Umur } \\
\hline$<35$ tahun & 100 & 50,5 & 98 & 49,5 & 0,723 \\
\hline$\geq 35$ tahun & 18 & 47,4 & 20 & 52,6 & \\
\hline \multicolumn{6}{|l|}{ Paritas } \\
\hline Nulipara & 46 & 48,4 & 49 & 51,6 & 0,690 \\
\hline Bukan nulipara & 72 & 51,1 & 69 & 48,9 & \\
\hline \multicolumn{6}{|l|}{ Lama Persalinan } \\
\hline$\geq 12$ jam & 40 & 100 & 0 & 0 & 0,000 \\
\hline$<12 \mathrm{jam}$ & 78 & 39,8 & 118 & 60,2 & \\
\hline \multicolumn{6}{|l|}{ Trauma Perineum } \\
\hline Ya & 102 & 52,3 & 93 & 47,7 & 0,122 \\
\hline Tidak & 16 & 39 & 25 & 61 & \\
\hline \multicolumn{6}{|l|}{ Berat Janin } \\
\hline$\geq 4000$ gram & 14 & 70 & 6 & 30 & 0,062 \\
\hline$<4000$ gram & 104 & 48,1 & 112 & 51,9 & \\
\hline
\end{tabular}


Dari tabel 2 menunjukkan bahwa pada kedua kelompok beda cara persalinan tidak ada perbedaan usia, paritas, trauma perineum yang terjadi dan berat janin yang dilahirkan. Hanya faktor lama persalinan yang berbeda bermakna antara kedua kelompok, kelompok persalinan vakum ekstraksi mengalami persalinan lebih lama dibandingkan persalinan normal.

Tabel 3. Analisis bivariat hubungan jenis persalinan dengan kejadian retensi urin

\begin{tabular}{|c|c|c|c|c|c|c|}
\hline \multirow[t]{2}{*}{ Jenis Persalinan } & \multicolumn{4}{|c|}{ Retensi urin } & \multirow[t]{2}{*}{ RR (95\%) } & \multirow[t]{2}{*}{$p$} \\
\hline & Ya & $\%$ & Tidak & $\%$ & & \\
\hline Vakum ekstraksi & 38 & $(32,2)$ & 80 & $(67,8)$ & $2,71(1,55-4,73)$ & 0,000 \\
\hline Normal & $14(11,9)$ & 104 & $(88,1)$ & & & \\
\hline
\end{tabular}

Persalinan dengan alat vakum ekstraksi akan meningkatkan secara signifikan kejadian retensi urin, RR 2,71 (95\% Cl 1,55-4,73).

Tabel 4. Analisis bivariat hubungan variabel luar terhadap retensi urin

\begin{tabular}{llcccccc}
\hline No & Variabel & Ya & $\%$ & Tidak & $\%$ & $\mathrm{RR}(95 \% \mathrm{Cl})$ & $\mathrm{p}$ \\
\hline 1 & Paritas & & & & & & \\
& Nulipara & 30 & $(31,6)$ & 65 & $(68,4)$ & $2,02(1,24-3,28)$ & 0,004 \\
& Bukan nulipara & 22 & $(15,6)$ & 119 & $(84,4)$ & & \\
2 & Lama Persalinan & & & & & & \\
& $\geq 12$ jam & 22 & $(55)$ & 18 & $(45)$ & $3,59(2,33-5,53)$ & 0,000 \\
& <12jam & 30 & $(15,3)$ & 166 & $(84,7)$ & & \\
3 & Trauma perineum & & & & & & 0,037 \\
& Ya & 48 & $(24,6)$ & 147 & $(75,4)$ & $2,52(0,96-6,60)$ & \\
& Tidak & 4 & $(9,8)$ & 37 & $(90,2)$ & & 0,02 \\
& Berat Janin & & & & & & \\
& $\geq 4000$ gram & 9 & $(45)$ & 11 & $(55)$ & $2,26(1,30-3,92)$ & \\
& $<4000$ gram & 43 & $(19,9)$ & 173 & $(80,1)$ & & \\
\hline
\end{tabular}

Beberapa variabel luar yang meningkatkan risiko terjadinya retensi urin adalah paritas ( $R R$ 2,02; $95 \% \mathrm{Cl}$ 1,24-3,28), lama persalinan ( $R R$ 3,59; $95 \% \mathrm{Cl} 2,33-5,53$ ), trauma persalinan (RR 2,52; $95 \% \mathrm{Cl} 0,96-6,60)$ dan berat janin (RR 2,26; $95 \% \mathrm{Cl} 1,30-3,92)$.

Pada analisis multivariat, jenis persalinan (OR 2,07; 95\% Cl 0,93-4,63; $\mathrm{p}=0,074$ ), berat janin (OR 1,95; 95\% Cl 0,65-5,84; $p=0,23$ ) dan trauma perineum (OR 1,35; 95\% Cl 0,41-4,36; $p=0,614$ ) tidak meningkatkan risiko kejadian retensi urin secara bermakna. Lama persalinan (OR 3,71; 95\% Cl 1,55-8,86; $p=0,003$ ), dan paritas (OR 2,29; $95 \% \mathrm{Cl}$ 1,12-4,66; $\mathrm{p}=0,023)$ merupakan risiko yang meningkatkan kejadian retensi urin secara bermakna. Trauma perineum juga tidak bermakna terhadap kejadian retensi urin. 
Tabel 5. Analisis multivariat hubungan beberapa variabel luar dan variabel bebas terhadap kejadian retensi urin

\begin{tabular}{lcc}
\hline Variabel & OR $(95 \% \mathrm{Cl})$ & $\mathrm{P}$ \\
\hline $\begin{array}{l}\text { Jenis Persalinan } \\
\text { Vakum Ekstraksi }\end{array}$ & $2,07(0,93-4,63)$ & 0,074 \\
$\quad$ Normal & & \\
$\begin{array}{l}\text { Lama persalinan } \\
\geq 12 \text { jam }\end{array}$ & $3,71(1,55-8,86)$ & 0,003 \\
$\quad<12$ jam & & \\
$\begin{array}{l}\text { Paritas } \\
\quad \text { Nulipara }\end{array}$ & $2,29(1,12-4,66)$ & 0,023 \\
$\quad$ Bukan nulipara & & \\
$\begin{array}{l}\text { Berat Janin } \\
\quad \text { 4000 gram }\end{array}$ & $1,95(0,65-5,84)$ & 0,230 \\
$\quad<4000$ gram & & \\
$\begin{array}{l}\text { Trauma Perineum } \\
\text { Ya }\end{array}$ & $1,35(0,41-4,36)$ & 0,614 \\
$\quad$ Tidak & & \\
\hline
\end{tabular}

Kejadian retensi urin pada Persalinan dengan vakum ekstraksi sebesar $32,2 \%$, lebih tinggi dibandingkan dengan kejadian retensi urin pada persalinan normal yaitu 11,9 Kejadian retensi urin pada vakum ekstraksi ,nilai $p=0,074$ dengan $\mathrm{OR} 2,07,95 \% \mathrm{Cl} 0,93-4,63$ ) artinya tidak ada hubungan yang bermakna antara persalinan dengan vakum ekstraksi dan kejadian retensi urin dan persalinan dengan vakum ekstraksi akan meningkatkan risiko 3 kali terjadinya retensi urin. Hal ini disebabkan karena setelah dilakukan analisis multivariat regresi logistik, lama persalinan sebagai variabel luar sangat mempengaruhi kejadian retensi urin sehingga vakum ekstraksi sebagai variabel bebas menjadi tidak bermakna secara statistik.

Tindakan vakum ekstraksi dan persalinan yang lama menyebabkan trauma mekanik yaitu berupa peregangan jaringan dinding dasar pelvis dan meningkatkan udem perineal serta menyebabkan kerusakan nervus pudendus dan berujung pada gangguan berkemih. ${ }^{4}$
Kejadian retensi urin lebih banyak pada kelompok nulipara, yaitu sebesar 30 ( 31,6\%) dibanding $22(15,6 \%)$, dengan nilai $p=0,023$, dan OR 2,29, 95\% Cl 1,12-4,66) artinya ada hubungan bermakna antara paritas dengan kejadian retensi urin dan primiparitas meningkatkan risiko hampir tiga kali terjadinya retensi urin. Carley et al. menyebutkan bahwa kejadian retensi urin lebih banyak pada primigravida dibanding multigravida $(p<0,001)$ dan primigravida lebih banyak pada kelompok persalinan yang menggunakan vakum ekstraksi dibanding dengan kontrol (47,1\%vs $12,4 \% ; p<0,001)$. Primigravida lebih banyak menerima episiotomi $(p=0,001) .^{5}$

Kejadian retensi urin lebih banyak pada kelompok lama persalinan $\geq 12$ jam yaitu $55 \%$ dibanding $15,3 \%$. Dengan nilai $p=0,003$ dan OR $3,71(95 \% \mathrm{Cl} 1,55-8,86)$ artinya ada perbedaan bermakna antara lama persalinan 12 jam dengan kejadian retensi urin dan lama persalinan $\geq 12$ jam meningkatkan risiko hampir 4 kali terjadinya retensi urin. Kekre et al. menyebutkan retensi urin berhubungan signifikan dengan persalinan instrumen dan durasi persalinan lebih dari 700 menit dengan nilai $p<0,001$ dan OR 1,003 (95\% $\mathrm{Cl}$ 1,003-1,004). ${ }^{1}$ Pada sebuah studi dilaporkan durasi persalinan 11 jam 40 menit mempunyai hubungan signifikan dengan retensi urin postpartum. Trauma mekanik dari persalinan yang lama atau persalinan dengan instrumen dapat meningkatkan udema perineum dan memacu kesulitan berkemih. ${ }^{6}$

Kejadian retensi urin lebih banyak pada kelompok dengan trauma perineum yaitu $24,6 \%$ dibanding 9,8\% pada kelompok yang tidak mengalami trauma., dengan nilai $p=0,614$ dan OR 1,35 (95\% Cl 0,41-4,36), artinya tidak ada hubungan bermakna antara trauma perineum dengan kejadian retensi urin dan trauma perineum meningkatkan risiko hampir 1 setengah kali terjadinya retensi urin postpartum. Kerusakan nervus pudendus dapat mengganggu 
input afferent ke kandung kemih dan menggangu refleks relaksasi dasar pelvis dan sphincter urethra. ${ }^{6}$

Episiotomi dan laserasi jalan lahir berhubungan dengan peningkatan insidensi retensi urin postpartum. Kekre et al. menyebutkan pada penelitiannya episiotomi dan laserasi jalan lahir tidak meningkatkan insidensi retensi urin postpartum $(p=0,08)$ dan $(p=0,44) .^{1}$ Kejadian retensi urin lebih banyak pada pasien dengan berat janin $\geq 4000 \mathrm{gr}$ yaitu $45 \%$ dibanding dengan $19,9 \%$ pada kelompok yang berat janin < 4000gr, dengan nilai $\mathrm{p}=0,230$ OR 1,95 $(95 \% \mathrm{Cl} 0,65-5,84)$, artinya tidak ada hubungan yang bermakna antara berat janin $\geq 4000 \mathrm{gr}$ dengan kejadian retensi urin, dan berat janin $\geq 4000 \mathrm{gr}$ meningkatkan risiko hampir 2 kali terjadinya retensi urin postpartum. Pada penelitian sebelumnya Handler et al.,(2011) melaporkan bahwa berat janin tidak berhubungan dengan kejadian retensi urin postpartum. ${ }^{7}$ Pada penelitian lain Lim et al.,(2009) melaporkan bahwa berat badan lahir tidak berhubungan bermakna dengan kejadian retensi urin postpartum, nilai $p=0,62, O R \quad 0,98$, $95 \% \mathrm{Cl} 0,99-1,00{ }^{8}$

Retensi urin postpartum dapat menyebabkan kerusakan yang ireversibel dari muskulus detrusor dan serabut saraf parasimpatis yang menginervasi kandung kemih yang menggangu fungsi muskulus detrusor. ${ }^{9}$ Ching-chung et al. menggambarkan komplikasi jangka panjang seperti stres inkontinensia urin dan instabilitas detrusor pada wanita dengan retensi urin postpartum yang resisten. ${ }^{10}$

\section{KESIMPULAN DAN SARAN}

Kejadian retensi urin lebih tinggi pada persalinan vaginal dengan vakum ekstraksi dibanding persalinan normal. Faktor luar yang berpengaruh terhadap kejadian retensi urin yaitu lama persalinan dan paritas. Dari penelitian ini disarankan bahwa kejadian retensi urin dapat ditekan bila proses persalinan yang lama dan paritas yang tinggi dapat dicegah.

\section{DAFTAR PUSTAKA}

1. Kekre NA, Vijayanand S, Dasgupta R, Kekre N, Postpartum Urinary Retention after Vaginal Delivery, 2011.International Journal of Gynecology and Obstetrics, 112 (2): 112-115

2. Yustini E, dkk. Efektifitas bladder training terhadap BAK spontan postpartum. Majalah Obstetri Ginekologi Indonesia. 2008;32:4.

3. Rizvi RM and Rizvi J, Management of Postpartum Urinary Retention, 2006. Review in Gynaecological and Perinatal Practice, 6(3-4): 140-144

4. Rahmanou P, Postpartum Bladder Care: Background, practice and complication, University College London Hospital Trust, London, 2011.

5. Carley ME, Carley JM, Vasdev G, Lesnick TG, Webb MJ, Ramin KD and Lee RA, Factors that are associated with clinically overt postpartum urinary retention after vaginal delivery, 2002. Am J Obstet Gynecol 187(2):430-433.

6. Chaliha C, Postpartum Bladder Dysfunction, 2006. Review in Gynaecological and perinatal practice, 6(3-4): 133-139

7. Handler, SJ, Cheng, YW, Knight, S., Lyell, D., Caughey, $A B$, What factors are associated with postpartum urinary retention?, 2011. American Journal of Obstetrics and Gynecology. 204():S79

8. Lim, JL. Post-partum voiding dysfunction and urinary retention, 2010. Australian and New Zealand Journal of Obstetrics and Gynaecology 50(3): 502-505

9. Liang CC, Chang SD, Chang YL, Chen SH, Chueh HY, Cheng PJ, Postpartum Urinary retention after Cesarean Delivery, 2007. International Journal of Gynecology and Obstetrics 99( 3): 229-232

10. Ching-Chung L, Shuenn-Dhy C, Ling-Hong T, Ching C, Chao-Lun C, Po-Jen C. Postpartum urinary retention: assessment of contributory factors and long term clinical impact. Aust NZ J Obstet Gynecol 2002;42(4):365-8 